School 1 (both $\mathrm{P}<0.001$ ). Among the boys, total activity was higher in School 2 than in School 1 and School 3 (both $\mathrm{P}=0.02$ ) with mean (standard deviation) units of activity a week of 39.1 (6.8), 34.7 (7.7), and 33.8 (7.8).

In general, girls did less physical activity a week than boys (32.7 (6.8) v 35.9 (7.7) units; $\mathrm{P}=0.007)$, but their patterns according to school were the same. Mean household incomes were 5.5, 4.3, and 2.7 units in the three schools (all $\mathrm{P}<0.001$ ).

\section{Comment}

The total amount of physical activity done by primary school children does not depend on how much physical education is timetabled at school because children compensate out of school. This is unexpected, but encouraging, because the amount of timetabled physical education offered in School 1 is unlikely to be bettered elsewhere, and children from School 3 (the poorest) were not adversely affected. Less encouraging is that girls do significantly less physical activity than boys yet are known to have higher insulin resistance and triglyceride levels. ${ }^{4}$ It may be relevant that more girls than boys develop type 2 diabetes in childhood.

We cannot comment on whether physical activity among primary school children has declined, but we found no evidence that children from poorer backgrounds are adversely affected-they recorded the same overall physical activity as the most privileged children. The survey by Sport England was conducted by questionnaire, and its conclusions differ from ours. ${ }^{1}$ We will publish data on the intensity of physical activity and metabolic health of the children elsewhere. Our findings need confirmation but give cause for reflection on methods of collecting activity data, the provision of physical education in school, and the competing demands of the school curriculum.

Our study is part of EarlyBird, a 12 year programme investigating childhood factors which lead to diabetes in later life. We thank Claire Snow for collecting and inputting the data and Jonathan Williams for inputting the data.

Contributors: TJW and LDV conceived the study. KMM, TJW, and LDV designed the study. KMM collected and managed the data. KMM, BSM, and JK analysed the data. All authors interpreted the data and wrote the paper. TJW is the guarantor. Funding: South and Southwest NHS Executive Research and Development.

Competing interests: None declared.

Ethical approval: Plymouth local research ethics committee of the South and West Devon Health Authority.

1 Rowe N, Champion R. Young people and sport national survey 1999. London: Sport England, 2000.

2 Ekelund U, Sjostrom M, Yngve A, Poortvliet E, Nilsson A, Froberg K, et al. Physical activity assessed by activity monitor and doubly labelled water in children. Med Sci Sports Exerc 2001;33:275-81.

3 Metcalf BS, Curnow JS, Evans C, Voss LD, Wilkin TJ. Technical reliability of the CSA activity monitor (EarlyBird 8). Med Sci Sports Exerc 2002;34:1533-7.

4 Murphy MJ, Mallam KM, Voss LD, Jeffery AN, Kirkby J, Wilkin TJ. Girls at five are intrinsically more insulin resistant than boys: the programming hypotheses revisited (EarlyBird 6). Pediatrics. In press.

(Accepted 17 April 2003)

\title{
Severe traffic injuries to children, Trent, 1992-7: time trend analysis
}

\author{
Carol Coupland, Julia Hippisley-Cox, Denise Kendrick, Lindsay Groom, Elizabeth Cross, \\ Boki Savelyich
}

Unintentional injury is the leading cause of death in children aged 1 to 15, and two thirds of fatal injuries in schoolchildren result from road traffic crashes. ${ }^{1}$ More than $75 \%$ of children fatally or seriously injured in road traffic crashes are pedestrians or cyclists.

Socioeconomic gradients exist in children admitted with pedestrian and pedal cycle injuries, ${ }^{2}$ but little is known about trends in these gradients over time. We examined trends in admission rates and socioeconomic gradients for traffic injuries in children between 1992 and 1997.

\section{Participants, methods, and results}

We considered children aged 0-14 years who were admitted to hospital for pedal cycle, pedestrian, or other transport injuries in the 862 electoral wards in the old Trent NHS Executive Region, United Kingdom, between 1 April 1992 and 31 March 1997. An admission for fracture of a long bone needing an operation was a severe injury. ${ }^{3}$ We allocated each patient to their electoral ward using their postcode, aggregated the data at ward level for each year of the study, and calculated admission rates in each ward using population data.

We used random effects Poisson regression to find rate ratios for changes in admission rates and socioeconomic gradients over the study period. We categorised wards into fifths using the Townsend score for each ward. To assess whether the socioeconomic gradients had changed over the study period we conducted tests for interaction. Confounding variables were rurality, proportion of boys in the ward, proportion of black and Asian residents, and distance from the centre of the ward to the nearest acute hospital trust.

During the study period, admissions of children with severe injuries from road traffic crashes were 1061 pedal cyclists, 449 pedestrians, and 426 others. Admission rates for severe injuries among cyclists and pedestrians increased by $4.9 \%$ (95\% confidence interval $0.6 \%$ to $9.5 \%)$ and $9.8 \%(2.9 \%$ to $17.3 \%)$ each year (table 1$)$. Conversely, admission rates for other severe injuries decreased by $10.8 \%$ (4.6\% to $16.7 \%$ ) each year. Socioeconomic gradients did not change significantly during the study period.
Division of Primary Care, University of Nottingham, Nottingham NG7 2RD Carol Coupland senior lecturer in medical statistics Julia Hippisley-Cox senior lecturer in general practice Denise Kendrick senior lecturer in general practice Lindsay Groom research unit coordinator Elizabeth Cross researcher in general practice

Boki Savelyich researcher in general practice

Correspondence to: C Coupland carol.coupland@ nottingham.ac.uk

BMJ 2003;327:593-4 
Severe injuries in children aged 0-14 years, Trent, 1992-7*

\begin{tabular}{|c|c|c|c|c|c|c|}
\hline & \multicolumn{5}{|c|}{ Yeart } & \multirow[b]{2}{*}{$P$ value for trend‡ } \\
\hline & 1992-3 & 1993-4 & $1994-5$ & 1995-6 & 1996-7 & \\
\hline \multicolumn{7}{|c|}{ Admission rates per 100000 population } \\
\hline Cyclists & 22.5 & 23.3 & 25.4 & 23.6 & 28.3 & 0.027 \\
\hline Pedestrians & 9.2 & 7.8 & 10.6 & 13.3 & 11.3 & 0.005 \\
\hline Other transport & 11.6 & 10.2 & 13.3 & 6.4 & 7.9 & 0.001 \\
\hline \multicolumn{7}{|c|}{ Socioeconomic rate ratios§ } \\
\hline Cyclists & $1.3(0.9$ to 2.0$)$ & $1.3(0.9$ to 2.0$)$ & 1.5 (1.0 to 2.2$)$ & $1.2(0.8$ to 1.9$)$ & $1.8(1.2$ to 2.6$)$ & 0.35 \\
\hline Pedestrians & 5.2 (2.2 to 12.2$)$ & $3.0(1.3$ to 7.1$)$ & 1.7 (0.9 to 3.2$)$ & 2.4 (1.3 to 4.5$)$ & 4.0 (1.9 to 8.2$)$ & 0.61 \\
\hline Other transport & $1.0(0.6$ to 1.8$)$ & $1.0(0.5$ to 1.8$)$ & $1.3(0.7$ to 2.2$)$ & $1.3(0.6$ to 2.8$)$ & 0.7 (0.3 to 1.3$)$ & 0.65 \\
\hline
\end{tabular}

${ }^{*} \mathrm{An}$ admission for fracture of a long bone needing an operation was a severe injury. †From 1 April to 31 March.

†Poisson regression.

§Values are incidence rate ratios (95\% confidence intervals) comparing injury admission rate in children in most deprived wards with those in least deprived, according to fifths of the distribution, adjusted for rurality, percentage boys aged 0-4 and 5-14, percentage black, percentage Asian, and distance from nearest hospital.

Admission rates for all traffic injuries in children increased by $8.1 \%$ (5.6\% to $10.7 \%)$ for pedal cyclists, did not change for pedestrians, and decreased by $13.9 \%(11.0 \%$ to $16.7 \%)$ for others.

\section{Comment}

Admission rates for severe injuries to pedal cyclists and pedestrians increased in children in Trent between 1992 and 1997, but admission rates for other transport injuries fell; socioeconomic gradients among those admitted did not change.

Our findings are surprising, given the increasing number of journeys made by car in this period. Perhaps children's safety improved for car passengers but not for pedestrians or pedal cyclists between 1992 and 1997.

Our results relate only to long bone fractures, so maybe trends for other injuries differ, although trends were similar for all admissions for pedal cycle and other transport injuries. We need to analyse trends after 1997 to confirm our findings.

Injuries to pedestrians and cyclists can be reduced by area-wide engineering or traffic calming measures, ${ }^{4}$ and cycle helmets reduce head injuries. ${ }^{5}$ As national initiatives are promoting walking and cycling among schoolchildren, implementation of effective measures such as these should be a priority for local authorities and primary care groups and trusts.

We thank Andy Nicholson and Howard Chapman from Trent NHS Executive for help extracting data on hospital admissions and Maura Bell and April McCambridge for helping process ethical approval.

Contributors: JH-C and DK initiated this analysis. CC analysed the data and produced the final draft of the paper. JH-C got ethical approval, designed the study, manipulated the data, interpreted the analysis, and drafted the paper. DK designed the study and drafted the paper. LG designed the study, managed the project, and manipulated the data. EC collected and manipulated the data. BS manipulated and interpreted the data. $\mathrm{JH}-\mathrm{C}$ and $\mathrm{CC}$ are guarantors.

Funding: Trent NHS Executive.

Competing interests: None declared.

1 Office for National Statistics. Mortality statistics: injury and poisoning London: ONS, 2001. (DH4.)

2 Hippisley-Cox J, Groom L, Kendrick D, Coupland C, Webber E, Savelyich B. Cross sectional survey of socioeconomic variations in severity and B. Cross sectional surey

Cryer PC Jarvis SN, Edwards P, Langley JD. Why the government was Crye PC, Jarvis SN, Edwan P, Langey JD. Why the govennont was right to change the our Health 2000;114:232-7.

Towner E, Dowswell T, Jarvis S. Updating the evidence: a systematic review of what works in preventing childhood unintentional injuries: part 1. Inj Prev 2001;7:161-4.

5 Thompson DC, Rivara FP, Thompson R. Helmets for preventing head and facial injuries in bicyclists. Cochrane Library. Issue 4. Oxford: Update Software, 1999: ab001855.

(Accepted 1 July 2003)

\section{Submitting articles to the $B M J$}

We are now inviting all authors who want to submit a paper to the $B M J$ to do so via the web (http://submit.bmj.com).

We have introduced Benchpress, our new web based manuscript tracking system, with the aim of streamlining our processes and providing better, quicker information for authors, reviewers, and editors.

Benchpress is a website where authors deposit their manuscripts and editors go to read them and record their decisions. Reviewers' details are also held on the system, and when asked to review a paper reviewers will be invited to access the site to see the relevant paper. The system is secure, protected by passwords, so that authors see only their own papers and reviewers see only those they are meant to. The system is run by Highwire Press, who host bmj.com, and is already being used by 30 journals, including most of the BMJ Publishing Group's specialist journals.

For authors in particular the system offers several benefits. The system provides all our guidance and forms and allows authors to suggest reviewers for their paper-something we'd like to encourage. Authors get an immediate acknowledgement that their submission has been received, and they can watch the progress of their manuscript. The record of their submission, including editors' and reviewers' reports, remains on the system for future reference.

Anyone with an internet connection and a web browser can use the system.

As with all new systems we expect a few teething problems, but the system itself offers extensive help, and the $B M J$ 's editorial office is geared up to help authors and reviewers if they get stuck. We see Benchpress as part of our endeavour to improve our service to authors and reviewers and, as always, we'd welcome feedback

Benchpress is accessed via http://submit.bmj.com or via a link from bmj.com 